EXTENDED REPORT

\title{
Prevalence of rheumatoid arthritis in France: 2001
}

\author{
F Guillemin, A Saraux, P Guggenbuhl, C H Roux, P Fardellone, E Le Bihan, \\ A Cantagrel, I Chary-Valckenaere, L Euller-Ziegler, R-M Flipo, R Juvin, J-M Behier, \\ B Fautrel, C Masson, J Coste
}

See end of article for authors' affiliations

....................

Correspondence to: Professor F Guillemin, EA 3444 School of Public Health, Faculty of Medicine BP 184, University of Nancy 1, 5405 Vandoeuvre-les-Nancy, France; francis.guillemin@ medecine.uhp-nancy.fr

Accepted 14 March 2005 Published Online First 30 March 2005

Background: Prevalence estimates of rheumatoid arthritis (RA) vary across Europe. Recent estimates in southern European countries showed a lower prevalence than in northern countries.

Objectives: To estimate the prevalence of RA in France in a multiregional representative sample in the year 2001.

Methods: A two stage random sample was constituted in seven areas (20 counties) from the national telephone directory of households and by the next birthday method in each household. Patientinterviewers, member of self help groups, were trained to administer telephone surveys using a validated questionnaire for case detection of inflammatory rheumatism, and conducted the survey under quality control. All suspected cases of RA were confirmed by their rheumatologist or by clinical examination. Prevalence estimates after probability sampling correction were standardised for age and sex (national census 1999).

Results: An average response rate of $64.7 \%$ (two stages combined) led to a total of 9395 respondents. Standardised prevalence was $0.31 \%$ (95\% confidence interval 0.18 to 0.48 ) for RA, $0.51 \%$ in women and $0.09 \%$ in men, with a higher age-specific prevalence in the 65-74 year age band. A geographical analysis of county clustering showed significant variation across the country.

Conclusion: This national multiregional cooperative study demonstrates the usefulness of working in association with patients of self help groups. It showed a similar prevalence of RA to that of the spondyloarthropathies estimated concomitantly during the survey. It provides a reliable basis for definition of population targets for healthcare delivery and drug treatments.

$\mathrm{T}$ he prevalence of chronic disease provides an indication of the burden of a disease, which is useful to health professionals and policy makers for healthcare planning. Variations in the prevalence of rheumatoid arthritis (RA) have been observed both over time and geographically. The hypothesis that the occurrence of RA has declined has been suggested in countries where epidemiological studies have been conducted in previous decades, particularly in the United Kingdom and America. ${ }^{1}$ The geographical distribution of prevalence estimates across Europe is uneven according to estimates in past decades, varying from $0.8-1 \%$ formerly in northern countries estimates to $0.3-0.5 \%$ recently in southern countries. Recently, a study, using an original survey method of community case detection by telephone interview conducted by patient-interviewer, followed by case confirmation, was conducted in Brittany, west France. It showed a 0.5\% prevalence rate. ${ }^{2}$ Since then, the method has been formalised, extensively tested in a nationwide survey, and its validity has been documented. ${ }^{3}$

Preliminary reports indicated that France might be in an intermediate situation within the European north-south gradient. With 60 millions inhabitants over 95 counties, a mix of ethnicities of various origin, and variance in environment and lifestyle across the country, this may lead to some heterogeneity of RA between regional areas.

Our objective was firstly, to estimate the point prevalence of RA in France, and secondly, to investigate whether there were regional differences within the country.

\section{MATERIAL AND METHODS}

A nationwide multistage sample survey was conducted in 20 counties distributed among various regions and piloted in seven investigating centres (fig 1). The survey was conducted using a validated method of telephone survey by patientinterviewer ${ }^{3}$ recruited in self help groups and trained by professional poll staff.

Areas for conducting the survey were selected on the basis of a widespread coverage of the population distribution over the country, in 20 counties grouped around seven investigating centres. Area of high urban concentration with a high rate of migratory movements, like Paris, were excluded from the survey.

The first stage of sampling was a random selection of numbers from the public telephone list to be dialled. Enterprise and business numbers as well as institutions for the elderly were excluded before dialling, as were second homes when identified on phone contact, to avoid redundancy.

The second stage of sampling was a random selection of adults in the household, using the next birthday method. ${ }^{4} \mathrm{~A}$ list of adults aged 18 or over in the household was obtained from the person answering the phone. The person with a birthday date closest to the interview date was then selected from this list and invited to answer the questionnaire. No particular exclusion criteria were applied.

The process of case ascertainment comprised case detection and case confirmation stages. Case detection was conducted by patient-interviewers using a validated detection questionnaire, ${ }^{3}$ which included 33 questions. Some of the main questions were "Have you now or have you had pain in your neck, your back, or your buttocks?", "Are you at present experiencing, or have you in the past experienced, pains in your joints?", and "What was the diagnosis?". According to this interview, any patient with suspected arthritis was further called by a physician rheumatologist who screened for diagnosis with a standardised form of signs and 
First step

Second step

Third step

Fourth step
Random selection of households telephone numbers $(n=15219)$<smiles>C1CCCCC1</smiles>

Exclusion of second home and place of work

Random selection of adults in households by next birthday method $(n=9395)$

Case detection by patient interviewers using a validated questionnaire (detection 1)

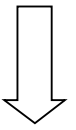

Patients with suspected RA were called by rheumatologists (detection 2) $(n=36)$

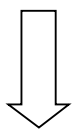

Patient's rheumatologist physician contacted (confirmation 1) ( $n=30)$

Patients without rheumatologist physician were invited

to the investigation centre (confirmation 2) $(n=6)$<smiles>C1CCCC1</smiles>

Rheumatoid arthritis confirmed $(n=32)$

Figure 1 Process of sampling (random selection of telephone numbers and random selection of adults in the households) and case ascertainment (case detection and case confirmation stages).

symptoms. If the diagnosis of RA could not be eliminated, the patient's rheumatologist physician was contacted to confirm diagnosis. Patients without a rheumatologist physician were invited to the investigation centre where they underwent complete rheumatological, laboratory, and $x$ ray examinations to ascertain or reject the diagnosis.

The sample size of the study was calculated on the basis of an expected low prevalence in some regions, with as low as $0.3 \%$ to be estimated with a $20 \%$ refusal rate. Accordingly, using a Poisson distribution assumption, 4000 people contacted by phone would provide a $95 \%$ confidence interval of 0.14 to $0.54 \%$ around a $0.3 \%$ estimate.

Calculation of estimates accounted for the two stage sampling procedure-that is, the proportion of the sample in each county population and the size of the household in each county sample. Standardised estimates were calculated based on age and sex distribution according to national census data 1999 (National Census, INSEE, http://insee.fr/, accessed 11 July 2005). The 95\% confidence interval was calculated using an approximation by a $\gamma$ distribution of the weighted sum of independent random Poisson variables, which provides a conservative confidence interval estimate whenever the standard population is not proportional to the study population. ${ }^{5}$ Statistical analysis was carried out with Sudaan software (SAS).

\section{RESULTS}

Among the 15219 selected anonymous telephone numbers, $3.6 \%$ were a business or second home. An average $64.7 \%$ of households agreed to participate in the survey and answered according to the next birthday method. Non-response rate differed significantly between counties (30.1 to $44.9 \%$; $\mathrm{p}<0.001)$. A total of 9395 people participated in the survey: in Bretagne-Ouest $(n=1695)$, Bretagne-Est $(n=1750)$, Nord-Picardie $(\mathrm{n}=1105), \quad$ Midi-Pyrénées $(\mathrm{n}=1264)$, Provence-Côte d'Azur $(\mathrm{n}=751)$, Lorraine $(\mathrm{n}=2024)$, Rhônes-Alpes $(\mathrm{n}=806)$. They were interviewed by a total of 110 patient-interviewers recruited and trained in the seven

Table 1 Survey population and sample age and sex distribution

\begin{tabular}{|c|c|c|c|c|c|c|c|c|}
\hline \multirow{2}{*}{$\begin{array}{l}\text { Age class } \\
\text { (years) }\end{array}$} & \multicolumn{4}{|c|}{ Sample, No (\%) } & \multicolumn{4}{|c|}{ Survey population, No (\%) } \\
\hline & Male & & Female & & Male & & Female & \\
\hline $18-24$ & 330 & (9.3) & 447 & (7.7) & 813033 & $(13.1)$ & 781534 & (11.5) \\
\hline $25-34$ & 684 & (19.2) & 960 & (16.4) & 1196527 & $(19.2)$ & 1189622 & (17.5) \\
\hline $35-44$ & 749 & (21.1) & 1051 & (18.0) & 1222913 & $(19.6)$ & 1239906 & (18.2) \\
\hline $45-54$ & 641 & (18.0) & 935 & (16.0) & 1156031 & $(18.6)$ & 1163015 & (17.1) \\
\hline $55-64$ & 409 & (11.5) & 829 & (14.2) & 745063 & (12.0) & 788476 & (11.6) \\
\hline $65-74$ & 488 & (13.7) & 897 & (15.4) & 663083 & $(10.6)$ & 831885 & (12.2) \\
\hline $75-84$ & 213 & (6.0) & 560 & (9.6) & 330166 & (5.3) & 532350 & (7.8) \\
\hline $85+$ & 40 & (1.1) & 162 & (2.8) & 100605 & (1.6) & 270309 & (4.0) \\
\hline Total & 3554 & (100) & 5841 & (100) & 6227421 & (100) & 6797097 & (100.0) \\
\hline
\end{tabular}


centres. Survey supervision and case confirmation were performed by 23 rheumatologists.

Among the 9395 people, 36 were suspected of some clinical presentation of RA at the case detection stage, of whom 32 were confirmed as RA, based on clinical diagnosis at the confirmation stage, whereas the diagnosis of RA in the other four was rejected at this stage. None refused to participate in the confirmation stage. Among the cases of definite RA, two were previously undiagnosed and confirmed by the investigating centre, where they were offered further treatment. Six patients did not have a diagnosis made by a rheumatologist and were confirmed after an outpatient visit to the investigating centre.

These 32 patients with RA ( 27 women, 5 men) had a mean age of 61.3 (11.0) years (range 29.9-78.9) and a median disease duration of 12.7 years.

The overall estimate of prevalence standardised for age and sex was $0.31 \%$ ( $95 \%$ confidence interval (CI) 0.18 to 0.48 ). It increased with age up to 75 years and showed a sharp decrease at older age (table 2). The prevalence was $0.51 \%$ ( $95 \%$ CI 0.27 to 0.82 ) for women and $0.09 \%$ (95\% CI 0.02 to 0.20 ) for men-a female to male ratio of 5.66 .

Estimates of standardised prevalence by region, ranged from 0.16 to $0.62 \%$, showing significant variation across the country, with lower prevalence in the northwest and higher prevalence in the southeast area $(\mathrm{p}=0.012)$.

\section{DISCUSSION}

This study of prevalence helps to highlight the burden of RA, as called for by the Bone and Joint Decade. ${ }^{6}$ According to current estimates, one can infer from our results that some 130000 adults (range 95000 to 210 000) have RA in France. This is important information for policy makers, professionals, and patients groups.

This is the first nationwide estimate in France, showing a low observed standardised prevalence of $0.31 \%$ overall, conducted in a representative sample over the country. Interestingly, these results are comparable to recent estimates published in southern Europe for Spain, ${ }^{7}$ Italy, ${ }^{8}$ and Greece. ${ }^{9}$

This estimate was obtained at relatively low cost, using a methodology that is reproducible and can be replicated in the future to examine trends. It is in line with a recent French estimate of a low prevalence, ${ }^{2}$ which was conducted with a smaller sample and wider $95 \%$ confidence interval. It is also congruent with a previous estimate of a low incidence in France. ${ }^{10}$ A shorter disease duration, possibly related to treatment, or less severe disease in more recent cohorts of incident cases could not be an explanation because biological agents had not yet been introduced on the French market at the time of the study, and less severe disease would only influence healthcare resources use, which was not considered for identification of cases. It is consistent with a European north-south slightly decreasing gradient, with northern estimates consistently about $0.5 \% .{ }^{11-13}$ As the performance sensitivity of the detection questionnaire used is $0.95,{ }^{3}$ and

\begin{tabular}{|lll|}
\hline $\begin{array}{l}\text { Table } 2 \\
\text { distribution }\end{array}$ & Prevalence of RA according to age \\
\hline Age class (years) & Rate $(\%)$ & $95 \% \mathrm{Cl}$ \\
\hline $18-24$ & 0.00 & \\
$25-34$ & 0.13 & 0.003 to 0.47 \\
$35-44$ & 0.11 & 0.003 to 0.39 \\
$45-54$ & 0.67 & 0.18 to 1.46 \\
$55-64$ & 0.44 & 0.14 to 0.89 \\
$65-74$ & 0.79 & 0.36 to 1.39 \\
$75-84$ & 0.10 & 0.002 to 0.36 \\
$85+$ & 0.00 &. \\
\hline
\end{tabular}

the specificity error was controlled for at the confirmation stage, the true prevalence in the French population may be as high as $0.326 \%$.

If one assumes an average life expectancy of 35 years at age of 50, a mean age of incident cases of 50, and a reduction of life by about 10 years due to RA in the estimates of the $1990 \mathrm{~s},{ }^{14}$ one would obtain by extrapolation a prevalence of around $0.3 \%$ at that time. Therefore, it must be concluded that the prevalence of the disease has not changed over this period.

The survey method was inexpensive as we obtained the collaboration of voluntary patient-interviewers. The phone survey by the interviewer was standardised by initial training by a professional poll staff company, and continuous monitoring of interview technique during the survey. Quality control was performed to check, for each interviewer, the percentage of households who refused to take part. The method is well suited for countries were telephone coverage is adequate. In France, more than $97 \%$ of households had telephones in 2001 (France-Telecom personal communication).

The method allows for the study to be carried out in other countries, and allows for a reasonably valid comparison with countries where population based RA registry data are available (UK, Norway). A similar survey conducted in an area which has a registry would provide more insight into the validity of the method used. Such a study has been conducted in the area of the ARC Manchester registry, using a physician administered questionnaire. ${ }^{15}$ The generalisation of the method in combination with a decennial population census would also improve the comparability of the data and improve knowledge about this disease.

The survey has some apparent limitations. Many people now only have a mobile phone, particularly young people. however, although use of mobile phones was growing rapidly at the time of the survey, most people still had a fixed line.

People in institutions were not reached by the survey, which probably biases estimates in the elderly, because elderly disabled people are more likely to be in an institution than those who are not disabled. This may explain the low prevalence found in those aged $>75$. The earlier mortality in $\mathrm{RA}^{14}$ also contributes to this low prevalence.

Measurement bias might have led to an underestimate of the prevalence. However, the procedure of clinical diagnosis and taxonomy are now well standardised. In a companion paper, ${ }^{16}$ which reports estimation of the prevalence of spondyloarthropathy obtained in the same survey, the figures for this disease were surprisingly higher than expected. ${ }^{16}$ One explanation might be that there is a long tradition in France of distinguishing in clinical practice between RA and peripheral forms of the spondyloarthropathies, thus leading to a better recognition of the latter and a lower prevalence estimate of the former.

Some people may have ignored the diagnosis of their condition. However, the survey identified and diagnosed two of the $34 \mathrm{RA}$, confirming the ability of the questionnaire to identify true cases.

This cross sectional prevalence study included all patients with active disease and those in remission, because the questionnaire asked about both current and past manifestations of the disease, and diagnoses made in the past. Therefore, it can be considered a cumulative prevalence, ${ }^{1}$ which is more useful for assessing geographical differences. A point prevalence of currently active disease may be more useful for planning healthcare provision, as it considers only those patients in current need of care.

The statistical power of this investigation was set to allow regional comparison based on a 0.14 to 0.54 confidence interval estimate. Our findings show a significant trend at the 
county level. ${ }^{17}$ The difference observed may be related to the small number of cases observed and sampling variations, although significant heterogeneity has been recently reported in Finland. ${ }^{18}$

Although the study provided an estimate of the prevalence of the disease, specific study designs are required to investigate the effect on disease development, of smoking habits, oral contraceptive use, diet, climate, or ethnicity, so as to avoid an ecological fallacy-that is, any apparent correlation of some overall level of population exposure with disease occurrence rate across counties in France, or across countries in Europe.

What this study does not provide is detailed information about the severity distribution of the disease, which is needed to identify those patients with severe disease who need more aggressive treatment like the newer biological agents. Given the low prevalence, population studies cannot answer these questions, although such studies enable the inclusion of patients with mild disease. The study indicates that there is no variation across the country, which suggests that resources for the treatment of RA should be distributed equally.

\section{ACKNOWLEDGEMENTS}

This survey was conducted with the active collaboration of the following investigators and interviewers in Amiens: G Clavel, JC Crépin; Brest: V Devauchelle, S Jousse, Grenoble: Ph Gaudin, B Gintz, E Rolland; Nancy: V Capron, F Doriat, S Etienne, G Fenot, MC Gautier, N Jay, D Loeuille, C Michel, J Pourel; Toulouse: B Navaud. We acknowledge the active collaboration of self help patients groups: ACSAC, AFLAR, AFP, AFS, ANDAR, ARP, Fibromyalgies, PALMA. A partnership was established with France-Telecom, and Institut CSA-TMO.

This survey was supported with an unconditional grant from Pharmacia, France, and a grant from the Société Française de Rhumatologie.

\author{
Authors' affiliations \\ F Guillemin, E Le Bihan, EA 3444, School of Public Health, Nancy, \\ France \\ A Saraux, Rheumatology, University Hospital, Brest, France \\ P Guggenbuhl, Rheumatology, University Hospital, Rennes, France \\ C H Roux, L Euller-Ziegler, Rheumatology, University Hospital, Nice, \\ France \\ P Fardellone, Rheumatology, University Hospital, Amiens, France \\ A Cantagrel, Rheumatology, University Hospital, Toulouse, France \\ I Chary-Valckenaere, Rheumatology, University Hospital, Nancy, \\ France \\ R-M Flipo, Rheumatology, University Hospital, Lille, France \\ R Juvin, Rheumatology, University Hospital, Grenoble, France \\ J-M Behier, Pharmacia, France \\ B Fautrel, Rheumatology, Pitié-Salpétrière University Hospital, Paris, \\ France
}

C Masson, Rheumatology, University Hospital, Angers, France J Coste, Biostatistics, Cochin University Hospital, Paris, France

Francis Guillemin, Alain Saraux, Pascal Guggenbuhl, Christian H Roux, Patrice Fardellone, Bruno Fautrel, Charles Masson, and Joel Coste are members of the epidemiology section of the Sociéte Française de Rhumatologie

\section{REFERENCES}

1 Silman A, Hochberg MC. Epidemiology of rheumatic diseases. Oxford: Oxford University Press, 2000

2 Saraux A, Guedes C, Allain J, Devauchelle V, Valls I, Lamour A, et al. Prevalence of rheumatoid arthritis and spondyloarthropathy in Brittany, France. J Rheumatol 1999;26:2622-7.

3 Guillemin F, Saraux A, Fardellone P, Guggenbuhl P, Behier JM, Coste J, et al. Detection of cases of inflammatory rheumatic disorders: performance of a telephone questionnaire designed for use by patient interviewers. Ann Rheum Dis 2003;62:957-63.

4 Salmon CT, Nichols JS. The next-birthday method of respondent selection. Public Opinion Quarterly 1983:47:270-6.

5 Fay MP, Fever EJ. Confidence intervals for directly standardized rates: a method based on the gamma distribution. Stat Med 1997;16:791-801.

6 WHO. Scientific Group on the Burden of Musculoskeletal Conditions at the Start of the New Millennium. The burden of musculoskeletal conditions at the start of the new millennium. World Health Organ Tech Rep Ser 2003;919:i-x, 1-218.

7 Carmona L, Villaverde V, Hernandez-Garcia C, Ballina J, Gabriel R, Laffon A, et al. The prevalence of rheumatoid arthritis in the general population of Spain. Rheumatology (Oxford) 2002;41:88-95.

8 Cimmino MA, Parisi M, Moggiana G, Mela GS, Accardo S. Prevalence of rheumatoid arthritis in Italy: the Chiavari Study. Ann Rheum Dis 1998:57:315-18.

9 Drosos AA, Alamanos I, Voulgari PV, Psychos DN, Katsaraki A, Papadopoulos I, et al. Epidemiology of adult rheumatoid arthritis in northwest Greece 1987-1995. J Rheumatol 1997;24:2129-33.

10 Guillemin F, Briancon S, Klein JM, Sauleau E, Pourel J. Low incidence of rheumatoid arthritis in France. Scand J Rheumatol 1994;23:264-8.

11 Kvien TK, Glennas A, Knudsrod OG, Smedstad LM, Mowinckel P, Forre O. The prevalence and severity of rheumatoid arthritis in Oslo. Results from a county register and a population survey. Scand J Rheumatol 1997;26:412-18.

12 Symmons D, Turner G, Webb R, Asten P, Barrett E, Lunt M, et al. The prevalence of rheumatoid arthritis in the United Kingdom: new estimates for a new century. Rheumatology (Oxford) 2002;41:793-800.

13 Simonsson M, Bergman S, Jacobsson LT, Petersson IP, Svensson B. The prevalence of rheumatoid arthritis in Sweden. Scand J Rheumatol 1999;28:340-3.

14 Coste J, Jougla E. Mortality from rheumatoid arthritis in France, 1970-1990. Int J Epidemiol 1994;23:545-52.

15 MacGregor AJ, Riste LK, Hazes JM, Silman AJ. Prevalence of rheumatoid arthritis in black-Caribbeans compared with whites in inner city Manchester. Ann Rheum Dis 1994:53:293-7.

16 Saraux A, Guillemin F, Guggenbuhl P, Roux CH, Fardellone P, Le Bihan E, et al. Prevalence of spondyloarthropathies in France: 2001. Ann Rheum Dis 2005;64: 1431-5.

17 Roux CH, Saraux A, Cost J, Guggenbuhl P, Fardellone P, Fautrel B, et al. Geographical variations of the prevalence of inflammatory rheumatism in France [abstract]. Arthritis Rheum 2003;48(suppl 9):967.

18 Kaipiainen-Seppanen O, Aho K, Nikkarinen M. Regional differences in the incidence of rheumatoid arthritis in Finland in 1995. Ann Rheum Dis $2001 ; 60: 128-32$. 